\title{
Substrate optimization for cultivation of Pleurotus ostreatus on lignocellulosic wastes (coffee, sawdust, and sugarcane bagasse) in Mizan-Tepi University, Tepi Campus, Tepi Town
}

\author{
Dagnew Bitew Tarko*, Abel Mandefro Sirna \\ Department of Biology, Mizan-Tepi University, Tepi, Ethiopia.
}

\begin{tabular}{|c|c|}
\hline $\begin{array}{l}\text { Article history: } \\
\text { Received on: October 16, } 2017 \\
\text { Accepted on: February 02, } 2018 \\
\text { Available online: May 22, } 2018\end{array}$ & $\begin{array}{l}\text { Tepi town is rich in lignocellulosic wastes such as coffee waste }(\mathrm{Cw}) \text {, sawdust }(\mathrm{Sd}) \text {, and sugarcane bagasse }(\mathrm{Sb}) \\
\text { which possibly used as mushroom substrate. Therefore, the purpose of this study was to assess the suitability of } \\
\text { three locally available substrates (Cw, Sd, and } \mathrm{Sb} \text { ) and their combinations for the cultivation of Pleurotus ostreatus } \\
\text { (Jacq. ex Fr.) P. Kummer. Spawn was prepared with sorghum supplemented with } 5 \% \text { wheat bran and } 1 \% \text { gypsum. }\end{array}$ \\
\hline $\begin{array}{l}\text { Key words: } \\
\text { Biological efficiency, } \\
\text { Lignocellulosic waste, } \\
\text { Pleurotus ostreatus (Jacq. ex Fr.) } \\
\text { P. Kummer, Spawn, } \\
\text { Substrate optimization. }\end{array}$ & $\begin{array}{l}\text { Main substrates were weighed, soaked in water, and steam sterilized for } 1 \mathrm{~h} \text { in plastic bags and inoculated with } \\
\text { fully grown spawn. All inoculated bags were arranged in completely randomized design on shelves in mushroom } \\
\text { growing room at ambient temperature }\left(23 \pm 2^{\circ} \mathrm{C}\right) \text {. Following days taken for complete mycelial colonization, pinhead } \\
\text { formation, fruit body formation and maturation, biological efficiency (BE), stipe length, and pileus diameter of } \\
\text { mature mushroom were recorded and analyzed using SPSS version } 16 \text {. Majority of substrate showed significant } \\
\text { variation in days taken for mycelial colonization, pinhead formation, and BE at } P \leq 0.05 \text {, whereas incubation periods } \\
\text { between flushes, stipe length and pileus diameter were not significantly varied. Despite lignocellulosic waste being a } \\
\text { menace to the environment represent a potential bioresource for production of oyster mushrooms. }\end{array}$ \\
\hline
\end{tabular}

\section{INTRODUCTION}

\subsection{Background}

On the surface of our planet, around 200 billion tons per year of organic matter are produced through the photosynthetic process [1]. Moreover, huge amounts of agricultural wastes and industrial by-products are produced worldwide from farm practices and industrial food products, respectively. Likely in Ethiopia, large amounts of lignocellulosic wastes are generated through agro-industrial activities in each year. However, the majority of this organic matter is not directly edible by humans and animals and, in many cases, disposed into the environment without any treatment. This leads to serious environmental pollution, which is world's current burning issue, though they are rich in organic compounds that are worthy of being recovered and transformed into value-added products [2].

Organic waste despite being a menace to the environment, they represent a potential bioresource for the production of various values added biomass-based byproducts such as food in the form of

*Corresponding Author

Dagnew Tarko Bitew, Department of Biology,

Mizan-Tepi University, Tepi, Ethiopia.

Email: btdagne@gmail.com mushroom, animal feed, bioenergy, biofertilizer, and other bio-based products [2,3]. Biorefining process such as mushroom cultivation is the current economically viable biotechnology, which involves the production of protein-rich food (mushroom) from materials that would otherwise consider as "waste," and being a means to overcome food insecurity, challenging issue in low- and middle-income countries [4]. Hence, nowadays, mushroom cultivation technology is being a promising candidate to fight food insecurity along with the reduction of environmental pollution apart from their nutritional and medicinal value they have [5].

Due to this fact, mushroom cultivation technology regard as the most profitable business, environmentally friendly, and short biological process of food protein (mushroom) recovery utilizing the degrading capabilities of mushroom fungi [6,7]. Among mushroom fungi, Pleurotus species reveal high efficiency in degradation of a wide range of lignocellulosic residues such as wheat straw, cotton wastes, coffee pulp, corn cobs, sunflower seed hulls, wood chips and sawdust, peanut shells, vine prunings, and others into mushroom protein, [8] the productivity of the conversion being expressed by biological efficiency (BE) [9].

Although there is huge amount of lignocellulosic wastes, high diversity of wild edible mushrooms and mushrooms is regard as national necessity to combat poverty and malnutrition in Ethiopia [10], there 
are only very few research-based practices in some parts of the country which are still at the stage of trials [11]. Thus, to provide an alternative source of food and food additives along with sustainable waste utilization for environmental protection strategy, this research aims to assess the suitability of three 125-1479271682_RVZ-5_20180308_V3 and their combinations for the cultivation of Pleurotus ostreatus (Jacq. ex Fr.) P. Kummer.

\section{MATERIALS AND METHODS}

\subsection{Study Area and Period}

The study was conducted at Mizan-Tepi University, Tepi campus, Tepi town, South Nations Nationalities and Peoples Regional State, Ethiopia. The study was conducted from November 2016 to May 2017. Tepi is located at $611 \mathrm{~km}$ south-west of Addis Ababa, capital city. The area is characterized by receiving high amount of annual rainfall, high humidity, and relatively large area vegetation coverage [12].

\subsection{Culture Source}

The pure culture of $P$. ostreatus (Jacq. ex Fr.) P. Kummer was obtained from Menagesha Integrated Organic Farm, Addis Ababa.

\subsection{Pure Culture Identification and Maintenance}

Obtained pure culture of $P$. ostreatus (Jacq. ex Fr.) P. Kummer from the source(s) was transferred into sterile Malt Extract Agar (MEA) plates and slants and it was authenticated by microscopic and macroscopic features. Then, plate and slant cultures were kept in a refrigerator for further use.

\subsection{Spawn Production}

Sorghum was used for spawn preparation. It was purchased from local market, dried by sun and about 3-4 $\mathrm{kg}$ of sorghum was weighed, washed 3 times with tap water; dead floated seeds were removed and soaked in water for $48 \mathrm{~h}$. Then, after the moisture content of the grain reached to $50-60 \%$, water was drained off and made the seed water free. Spawn substrate was formulated by mixing $94 \%$ of sorghum with 5\% wheat bran (purchased from Misrak Flour Industry at Addis Ababa) and 1\% gypsum. Formulated substrate was then packed in $500 \mathrm{ml}$ volume glass jars living air space at the top of the glass jar [13]. Approximately, each jar's 3/4 volume was filled with spawn substrate. Then, substrate from each jar was sterilized in autoclave at $121^{\circ} \mathrm{C}$ and 15 psi for $1 \mathrm{~h}$. Jars containing sterile substrate grains were allowed to cool and then inoculated aseptically by transferring 1-2 $\mathrm{cm}$ or blocks of 7-dayold fungal cultures sliced using sterile scalpels. Afterward, the jars were incubated at ambient temperature and visited in 3 days interval until the grains have been fully colonized by mycelia and turn white (cottony) in the jars [13].

\subsection{Mushroom Growing Room}

A $2 \mathrm{~m} \times 1 \mathrm{~m}$ mushroom growing room was prepared, in Mizan-Tepi University, Tepi campus, in front of Biology Department Laboratory. The room was made dark using cardboard and window sheet.

\subsection{Collection of Substrates}

Main substrates, namely, $\mathrm{Cw}$ (husks and pulp together), $\mathrm{Sd}$, and $\mathrm{Sb}$ were used. Sawdust from Cordia africana "Wanza" tree was collected from Tepi Wood Workshops, Tepi town. $\mathrm{Cw}$ was collected from coffee mill and Sb from sugarcane selling area in Ayer Meda, Tepi town. Supplementary substrate such as dung was also collected in Tepi town.

\subsection{Substrate Processing, Combination, and Formulation}

All substrates were dried in the sun for about a week. $\mathrm{Cw}$ and $\mathrm{Sd}$ were used directly while the $\mathrm{Sb}$ was broken into small pieces by machete. Primarily, each substrate means $\mathrm{Sd}, \mathrm{Cw}$ and $\mathrm{Sb}$ was used separately as main growth substrates with supplementary substrates. After observing the yield in each substrate, they were combined into different ratio (Cw50\%:Sb50\%, Cw50\%:Sd50\%, Sb50\%:Sd50\%, Cw50\%:Sb25\%:Sd25\%, Sb50\%:Cw25\%:Sd25\%, and Sd50\%:Cw25\%:Sb25\%) as growth substrates with 5\% animal dung as supplementary substrates. In addition, 1\% gypsum was used as additives so as to balance the $\mathrm{pH}$.

About $600 \mathrm{~g}$ dry weight of each of the main substrates and their combination was measured and soaked in water. After $24 \mathrm{~h}$ of soaking, the excess water was removed from the soaked substrate by decanting and squeezing with hand. The substrates were weighed again and adjusted to the appropriate moisture content (70-80\%). The moisture content was obtained by difference between the calculated percentage of dry and most weights of the substrate. Then, moist water free substrates and the combination of them were filled in clean separate heat-resistant polypropylene bags with supplementary substrates such as animal manure and gypsum [10]. The bags were labeled by the substrate type they contained and autoclaved at $121^{\circ} \mathrm{C}, 15 \mathrm{psi}$ for $1 \mathrm{~h}$, and then kept in a clean room for $12 \mathrm{~h}$ until they cooled down.

\subsection{Spawning}

For spawning, sterilized and cooled substrates from polypropylene bags were transferred into another ultraviolet ray sterilized transparent polyethylene bags. Thereafter, P. ostreatus (Jacq. ex Fr.) P. Kummer spawn was added into the polyethylene bag substrates using sterile spoons under laminar flow hood. Then, open end of the bags was closed with cotton and tied by rubber bands and numbers of small holes were made using sterile needle to allow air exchange of bags. Finally, all the bags were incubated at ambient temperature $\left(23 \pm 2^{\circ} \mathrm{C}\right)$ on shelves (made from wood) in a completely randomized design.

\subsection{Incubation of Inoculated Bags}

All inoculated bags were incubated in a complete darkness. Fresh air exchange between the dark room and the outside environment was allowed by opening windows at night. Then, after 3-4 days, each cultivating bags were irrigated using tap water every morning and evening until flushes of $P$. ostreatus fruiting bodies appear and 3 times per day after primordial formation. Plastic containers were filled with water and placed open at every corner of the dark room to maintain appropriate humidity in the room for the mycelial growth. In addition, water was sprayed on the walls, and approximately $70-80 \%$ humidity was maintained [14]. All treatment bags were inspected in each day to observe for contaminations that could happen. After 20 days of incubation, close observation of the bags was made to recognize complete spawn run and primordial formations [13].

\subsection{Induction of Fruit Body Formation}

According to Kivaisi [15], after the incubation period, when the bags were completely colonized by the mycelium, holes (approximately $2 \mathrm{~cm}$ in diameter) were made in the sides of bags to allow pinheads to emerge. The bags were watered 3 times a day and $70-80 \%$ humidity were maintained by spraying water on the walls of the room on a daily basis. 


\subsection{Harvesting of Mature Mushroom and Yield Assessment}

Mature mushrooms were collected by hand as well as scissor without damaging the substrate when they matured. In the present study, this was done for three consecutive flushes. During incubation between successive flushes, the bags were kept moistened until second and third flushes. Yield parameters were recorded with respect to time (days) taken for completion mycelial colonization, first appearance of pinhead formation, maturity of fruit bodies, pileus diameter and stipe length of matured mushroom, number of flushes, time interval between flushes, and yield/BE of flushes on the treatment substrates [16]. The pileus diameter and the stipe length of matured mushroom in each substrate type and flushing period were measured with graduated transparent ruler. Harvested mature mushrooms were weighed with analytical balance to determine the $\mathrm{BE}$ of mushrooms produced from substrates. The average BE of harvests was computed according to the following formula [17], and comparison was made among different substrates.

$\%$ yield $=\frac{\text { Weight of fresh mushroom harvested }}{\text { Dry weight of dry substrate before inculation }} \times 100$

\subsection{Data Analysis}

Recorded data were analyzed based on substrates type and yield parameters per flush using SPSS version 16.0. One-way analysis of variance was used to indicate significant mean differences among and within substrates at $95 \%$ confidence interval.

\section{RESULT}

\subsection{Spawn Making}

Sorghum is a suitable substrate for the production of oyster mushroom as it was reported so far. Spawn substrate composed of $94 \%$ sorghum, $5 \%$ wheat bran, and 1\% gypsum and had moisture content ranging between $50 \%$ and $60 \%$ and incubated at room temperature was taken 21 days for complete mycelial colonization of as indicated hereunder in Figure 1.

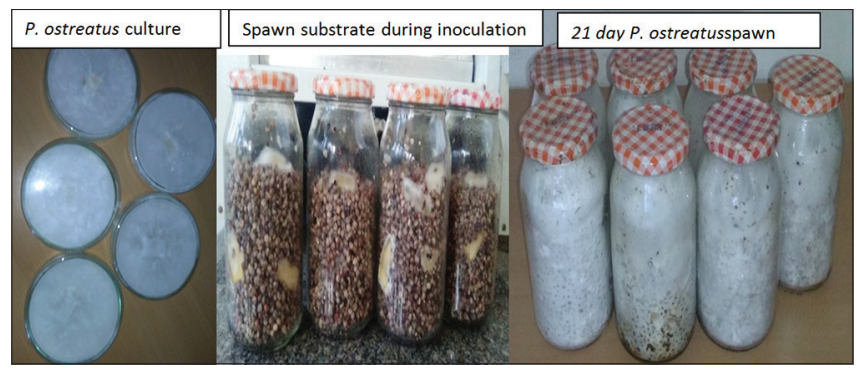

Figure 1: Pleurotus ostreatus (Jacq. ex Fr.) P. Kummer culture and spawn.

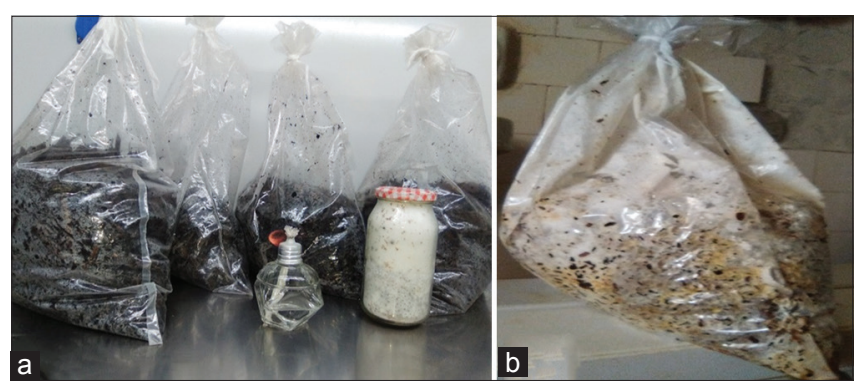

Figure 2: Spawning of sterilized substrates (a) complete mycelial colonization (b).

\subsection{Mycelial Colonization and Primordial Formation}

After spawning, all inoculated bags exhibited mycelia extension standing from the spawn grains into the cultivation substrate just after $24 \mathrm{~h}$ of spawning. Mycelia extension throughout the substrates was varied among different substrates, which implies the average days taken for complete mycelia colonization among substrates used were varied significantly. Complete colonization of the whole substrate was seen within the range of $13 \pm 1-19.3 \pm 0.57$ days. The highest mycelial invasion rate in complete colonization of the substrate was observed in $\mathrm{Sb}$ (13 \pm 1 days) followed by $\mathrm{Cw}_{50}: \mathrm{Sb}_{50}$ (13.7 \pm 0.58 days), $\mathrm{Cw}_{50}: \mathrm{Sb}_{25}: \mathrm{Sd}_{25}$ (14.2 \pm 1.5 days), $\mathrm{Sb}_{50}: \mathrm{Cw}_{25}: \mathrm{Sd}_{25}(15.6 \pm 1.2$ days), and $\mathrm{Cw}$ (16.3 \pm 1.52 days), whereas $\mathrm{Sd}$ showed the least rate of mycelial colonization and took the highest days $(19.3 \pm 0.57$ days) (exhibit lowest rate of mycelial running rate) after inoculation of spawn as indicated in Table 1 and Figure 2.

\subsection{Primordial Formation}

Similar to mycelial invasion, primordial formation and number of primordial were significantly different among different substrates. The first primordial appears after $20 \pm 1-29.7 \pm 0.6$ days of spawn inoculation. Lowest days were taken by $\mathrm{Sb}(20 \pm 1)$ and highest days were taken by $\mathrm{Sd}$ $(29.7 \pm 0.6)$ after spawning as indicated in Table 1 and Figure 3.

\subsection{Fruit Body Formation and Maturation Periods}

Duration for fruit body formation and maturation of fruit bodies after pinhead formation showed variations among different substrates and flush types ranging between $4 \pm 1$ and $7 \pm 0.5$ days. All substrates except $\mathrm{Sd}, \mathrm{Sb}_{50}: \mathrm{Sd}_{50}$ and $\mathrm{Sd}_{50}: \mathrm{Sb}_{25}: \mathrm{Cw}_{25}$ took 4-5 days from pinning to maturation of mushroom fruit body in the $1^{\text {st }}$ flushes as shown in Table 1. After 4 days, mushrooms became ready for picking as indicated in Figure 4.

\subsection{Harvesting of Matured Mushroom and Bioconversion Efficiency of Substrates}

Matured mushrooms were harvested by hand picking and scissor without harming the substrate. Mature mushrooms were harvested for

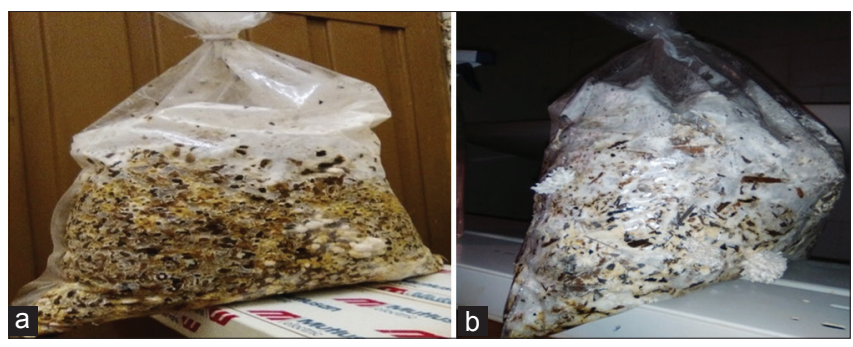

Figure 3: ( $a$ and $b$ ) Pinhead formation.

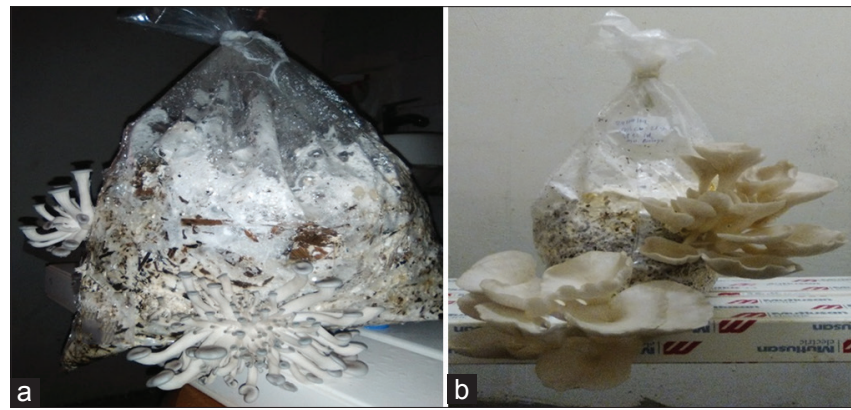

Figure 4: Immature fruit body (a) and mature fruit body of Pleurotus ostreatus (Jacq. ex Fr.) P. Kummer (b). 
three consecutive flushes but more than 3 times in some substrates. Mean weight of mature mushrooms harvested vary among different substrates and per flushes. Yield per flush and substrates showed statistically significant variations in all flushes at $P \leq 0.05$. The highest mean weight of mature mushrooms was obtained from the $\mathrm{Cw}$ substrate that is $318 \mathrm{~g}$ and followed by Sb and Cw50:Sb25:Sd25 which provide 300 and $271 \mathrm{~g}$ of mean weight of mature mushroom, respectively, and the least mean weight of mature mushroom is obtained from $\mathrm{Sd}$ which is $24 \mathrm{~g}$ which all are recorded in the first flush as indicated in Table 2 and Figure 5.
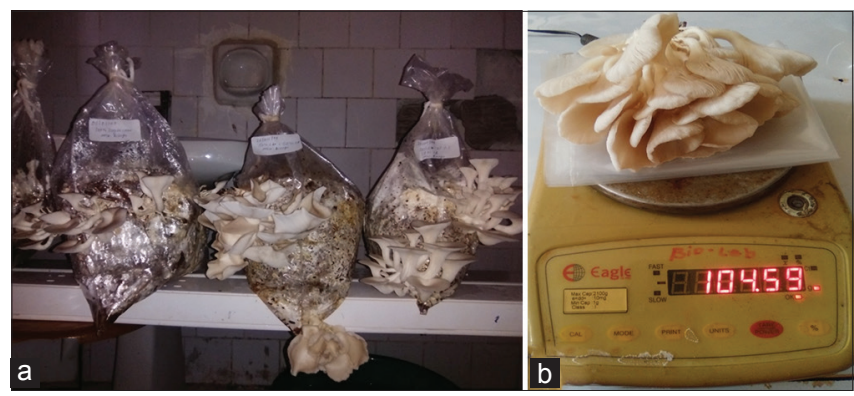

Figure 5: Mature mushroom in mushroom growing shelf and ready for harvesting (a) and weighing of harvested mushroom (b).

Table 1: Days taken for complete mycelial colonization, primordial formation, fruit body formation, and maturation.

\begin{tabular}{lccc} 
Substrate & $\begin{array}{c}\text { Complete mycelial } \\
\text { colonization (days) }\end{array}$ & $\begin{array}{c}\text { First } \\
\text { primordial } \\
\text { appearance } \\
\text { (days) }\end{array}$ & $\begin{array}{c}\text { Fruit body } \\
\text { formation and } \\
\text { maturation } \\
\text { after pinning } \\
\text { (days) }\end{array}$ \\
$\mathrm{CW}$ & $16.3 \pm 1.52^{\mathrm{a}}$ & $22.3 \pm 2.3^{\mathrm{a}}$ & $4 \pm 1^{\mathrm{a}}$ \\
$\mathrm{Sb}$ & $13 \pm 1^{\mathrm{b}}$ & $20 \pm 1^{\mathrm{a}}$ & $4 \pm 0.7^{\mathrm{a}}$ \\
$\mathrm{Sd}$ & $19.3 \pm 0.57^{\mathrm{a}}$ & $29.7 \pm 0.6^{\mathrm{b}}$ & $7 \pm 1.2^{\mathrm{b}}$ \\
$\mathrm{Cw}$ & $13.7 \pm 0.58^{\mathrm{b}}$ & $20.8 \pm 0.6^{\mathrm{a}}$ & $4 \pm 1.1^{\mathrm{a}}$ \\
$\mathrm{CW}_{50}: \mathrm{Sd}_{50}$ & $18.8 \pm 1.2^{\mathrm{a}}$ & $28.4 \pm 1.5^{\mathrm{b}}$ & $5 \pm 2^{\mathrm{a}}$ \\
$\mathrm{Sb}_{50}: \mathrm{Sd}_{50}$ & $18 \pm 1^{\mathrm{a}}$ & $27 \pm 2^{\mathrm{b}}$ & $6 \pm 1^{\mathrm{b}}$ \\
$\mathrm{CW}_{50}: \mathrm{Sb}_{25}: \mathrm{Sd}_{25}$ & $15.6 \pm 1.2^{\mathrm{b}}$ & $24 \pm 1^{\mathrm{a}}$ & $5 \pm 0.67^{\mathrm{a}}$ \\
$\mathrm{Sb}_{50}: \mathrm{Cw}_{25}: \mathrm{Sd}_{25}$ & $14.2 \pm 1.5^{\mathrm{b}}$ & $23.3 \pm 1.6 \mathrm{a}$ & $4 \pm 2^{\mathrm{a}}$ \\
$\mathrm{Sd}_{50}: \mathrm{Sb}_{25}: \mathrm{CW}_{25}$ & $17 \pm 1^{\mathrm{a}}$ & $26.4 \pm 1.5^{\mathrm{b}}$ & $6 \pm 1.5^{\mathrm{b}}$ \\
\hline
\end{tabular}

Mean values within a column sharing the same superscript letter are not significantly different at $P \leq 0.05$
Bioconversion efficiency (BE) of substrate showed statistically significant variation at $P \leq 0.05$ among substrate and flush types. $\mathrm{Cw}$, $\mathrm{Sb}$, and their combination provide relatively highest percentage of $\mathrm{BE}$, whereas sawdust of $C$. africana (Sd) gave the least percentage of $\mathrm{BE}$ in all consecutive flushes as indicated in Table 2.

\subsection{Pileus Diameter and Stipe Length}

Pileus diameter and stipe length of harvested matured oyster mushroom in each flush and treatment bags were measured with graduated transparent ruler and found insignificantly different among substrates at $P \leq 0.05$ as indicated hereunder in Table 3 .

Mean pileus diameter of mushrooms ranged from $5.5 \pm 0.5$ to $8 \pm 1.43 \mathrm{~cm}$. However, variations of pileus diameter among most substrates were not significant. Similarly, mean stipe length of mature mushrooms from different substrates were ranged in $4.89 \pm 1.8$ to $8.34 \pm 0.29 \mathrm{~cm}$ and variations among most substrates were not significant.

\subsection{Incubation and Fruit Body Maturation Period between Flushes}

As described in the above, matured oyster mushrooms were harvested for three consecutive flushes in all substrates. After harvesting, substrates were kept moist until pinning and fruit body formation. As indicated in Table 4, there is no statistically significant variation in incubation and maturation period (pining to fruit body maturation) between flushes at $P \leq 0.05$.

\section{DISCUSSION}

Lignocelluloses wastes represent huge amounts of unutilized renewable resource [18]. The large amount of lignocelluloses wastes is generated through forestry and agricultural practice, paper-pulp industries, timber industries, and many agro-industries and they pose an environmental pollution problem [19]. The cultivation of edible mushroom is a prime factor for the conversion of this low-value inedible waste into a higher value commodity, which can serve as alternative food source for humans and as a source of commercially important metabolites [18]. Furthermore, their spent can be used as cattle feed, fertilizer, or landfill [20]. Therefore, cultivation of mushroom on agroindustrial lignocelluloses waste provides multidisciplinary advantages for human being, animals, as well as for the ecosystem.

In spite of the presence of huge amount of lignocelluloses wastes and high diversity of wild edible mushrooms in Africa including

Table 2: Mean weight of fresh harvested mushroom and BE of substrate in each flush.

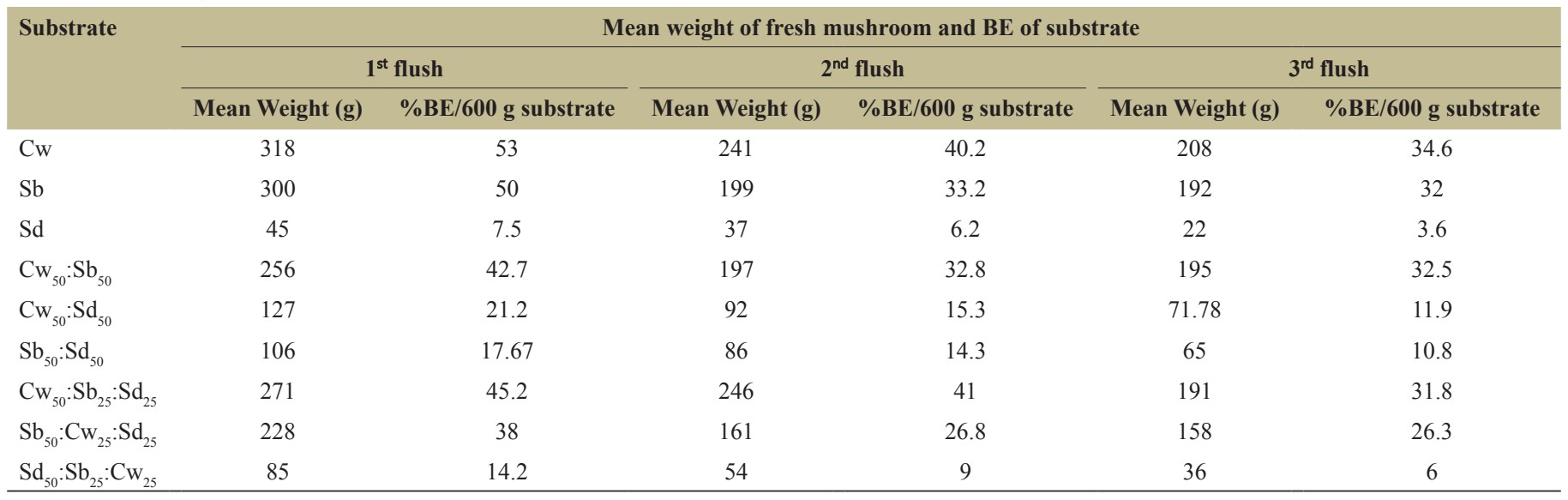


Table 3: Stipe length and pileus diameter of harvested mature mushroom.

\begin{tabular}{lcc} 
Substrate & Stipe length (cm) & Pileus diameter (cm) \\
$\mathrm{CW}$ & $8.34 \pm 0.29$ & $6.7 \pm 1.26$ \\
$\mathrm{Sb}$ & $7.67 \pm 3$ & $8 \pm 1.43$ \\
$\mathrm{Sd}$ & $5.93 \pm 0.26$ & $5.5 \pm 0.5$ \\
$\mathrm{Cw}_{50}: \mathrm{Sb}_{50}$ & $6.8 \pm 0.26$ & $7.3 \pm 1.72$ \\
$\mathrm{Cw}_{50}: \mathrm{Sd}_{50}$ & $4.89 \pm 1.8$ & $6.13 \pm 0.70$ \\
$\mathrm{Sb}_{50}: \mathrm{Sd}_{50}$ & $6.30 \pm 0.8$ & $6.9 \pm 0.96$ \\
$\mathrm{Cw}_{50}: \mathrm{Sb}_{25}: \mathrm{Sd}_{25}$ & $7.30 \pm 1$ & $7.03 \pm 0.25$ \\
$\mathrm{Sb}_{50}: \mathrm{Cw}_{25}: \mathrm{Sd}_{25}$ & $6.77 \pm 1.2$ & $6.4 \pm 0.66$ \\
$\mathrm{Sd}_{50}: \mathrm{Sb}_{25}: \mathrm{Cw}_{25}$ & $6.25 \pm 1$ & $6.56 \pm 0.37$ \\
\hline
\end{tabular}

Table 4: Incubation and fruit body maturation period between flushes.

\begin{tabular}{lcc} 
Substrate & $\mathbf{1 - 2}^{\text {nd }}$ flush (days) & $\mathbf{2 - 3}^{\text {rd }}$ flush (days) \\
$\mathrm{CW}$ & $9 \pm 1$ & $8.5 \pm 1.2$ \\
$\mathrm{Sb}$ & $8 \pm 1$ & $8 \pm 0.45$ \\
$\mathrm{Sd}$ & $11.5 \pm 2$ & $10 \pm 1.4$ \\
$\mathrm{Cw}_{50}: \mathrm{Sb}_{50}$ & $8.7 \pm 0.8$ & $8.3 \pm 0.5$ \\
$\mathrm{Cw}_{50}: \mathrm{Sd}_{50}$ & $10.8 \pm 1$ & $9.7 \pm 0.7$ \\
$\mathrm{Sb}_{50}: \mathrm{Sd}_{50}$ & $11 \pm 2$ & $11 \pm 1.9$ \\
$\mathrm{Cw}_{50}: \mathrm{Sb}_{25}: \mathrm{Sd}_{25}$ & $9.6 \pm 1.2$ & $9.2 \pm 1$ \\
$\mathrm{Sb}_{50}: \mathrm{Cw}_{25}: \mathrm{Sd}_{25}$ & $10.2 \pm 1$ & $10.9 \pm 0.9$ \\
\hline
\end{tabular}

Ethiopia, still very little of it is known. In general, southwest part of Ethiopia, in particular, the study area is rich in lignocellulosic wastes such as $\mathrm{Cw}$ (husk and pulp), $\mathrm{Sd}$, and $\mathrm{Sb}$ which possibly used as mushroom substrate. The present study indicated that $P$. ostreatus can be successfully grown on almost all aforementioned wastes and their combination, but pure coffee waste gave better results followed by pure $\mathrm{SB}$ and pure $C$. africana sawdust yield the least and showed inhibitory activity.

The first stage in any mushroom cultivation process is obtaining and maintenance of pure culture of the targeted mushroom species. Mushrooms can be grown on a variety of culture media. In the present study, MEA was used for tissue propagation of P. ostreatus (Jacq. ex Fr.) P. Kummer, which described as a good culture media for different mushroom species including the target mushroom species because of the presence of organic nitrogen [21].

The second stage in mushroom cultivation is the production of quality spawn. Modern methods of spawn preparation used cereal grains such as wheat, sorghum, maize, millet, and rye, which are sterilized in glass jars and then inoculated with interested mushroom strain and incubated at appropriate temperatures to allow complete mycelial colonization [22]. In the current study, sorghum supplemented with $5 \%$ wheat bran and $1 \%$ gypsum was used to produce spawn. Most reports showed that sorghum supplemented with wheat bran is of the best grain for the production of oyster mushroom spawn $[21,13]$ and also described that sorghum is a better available and cheaper than other substrates like maize in some areas in Africa including Ethiopia [13]. In the present study, the mycelium took 21 days to completely colonize the sorghum grain which is relatively shorter than the findings of Fekadu [23], that is, 25 days. However, it is within the ranges mentioned by Olumide [21].
Subsequently, after production and spawn inoculation was made, and whitish mycelia began to grow after $24 \mathrm{~h}$. In the current study, complete mycelial colonization periods of each substrate were recorded and complete mycelial invasion of the whole substrate was seen within the range of $13 \pm 1-19.3 \pm 0.57$ days. The highest mycelial invasion rate in complete colonization of the substrate was observed in $\mathrm{Sb}$ (13 \pm 1 days), followed by $\mathrm{Cw}_{50}: \mathrm{Sb}_{50}(13.7 \pm 0.58$ days $), \mathrm{Cw}_{50}: \mathrm{Sb}_{25}: \mathrm{Sd}_{25} 14.2$ \pm 1.5 days), $\mathrm{Sb}_{50}: \mathrm{Cw}_{25}: \mathrm{Sd}_{25}$ (15.6 \pm 1.2 days), and $\mathrm{Cw}$ (16.3 \pm 1.52 days), whereas Sd showed the least rate of mycelial colonization and took the highest days ( $19.3 \pm 0.57$ days) (exhibit lowest rate of mycelial running rate). Mycelial extension and colonization of hyphae throughout the substrate was varied on different substrates. The result of the present study was in disagreement with the study of Beje et al. [13], mentioned sawdust and combination of sawdust showed relatively shorter periods for complete mycelial colonization of the substrate, whereas coffee waste was taken longer periods and sawdust. However, in agreement with the study of Girmay et al. [24] which states that sawdust took the highest days (19.67 days) for complete mycelial running.

The time taken for mycelial extension of hyphae throughout the substrate was varied among different substrates used. The variation in the days taken for a spawning to complete colonization of a given substrate is a matter of the selected mushroom strain, incubation conditions, and cultivation substrate type [25]. This variation could, in turn, due to the variations in nutritious content/diversity and carbon to nitrogen ratio $(\mathrm{C}: \mathrm{N})$ of the substrates used [3].

After complete mycelial colonization, primordial appears and emerges through holes in the plastic bag. Different substrates showed different primordial formation periods ranging between $20 \pm 1$ and $29.7 \pm$ 0.6 days after spawn inoculation in $\mathrm{Sb}$ and $\mathrm{Sd}$ substrates, respectively. The time taken for the formation of pinheads is comparable with other similar studies elsewhere such as Ahmed [26] reported that pinhead formation of oyster mushroom took 23 and 27 days from spawning, while Fan et al. [27] reported 20-23 days.

The high variability of incubation periods (spawning to pinning and fruit body formation) of Pleurotus species was also reported by Iqbal et al. [16] in different substrates in which sugar bagasse took 16-23 days. Variability of pinning time may be due to the amount of spawn inoculated during spawning, temperature and relative humidity of the environment during incubation in mushroom growing room. Relatively higher room temperature resulted in shorter pining periods as comparable results obtained from Shah et al. [28] at $25^{\circ} \mathrm{C}$. In general, it takes longer period of incubation for oyster mushrooms at lower temperatures and relative humidity [29].

The last stage in mushroom cultivation is fruiting body production. Recent study indicated that several strain of mushroom has adapted to grow on a variety of substrates such $\mathrm{SB}$, coffee pulp, even the $\mathrm{BE}$ reached up to $63 \%$ [30] and hardwood chips [25]. In the present study, different amount of yields was obtained in different substrate and flush type and ranging between $7.5 \%$ and $53 \% \mathrm{BE}$ in the first flush. The highest yield was obtained in pure coffee waste $(53 \% \mathrm{BE})$ and the least was obtained from pure C. africana sawdust $(7.5 \% \mathrm{BE})$. The present study was in agreement with the study of Girmay et al. [24] states that $C$. africana sawdust yield the least (BE 9.7\%) but in disagreement with the study of Beje et al. [13]. This might be due to inaccessibility of lignocellulosic materials in the sawdust easily and/or low protein content which in turn imbalance $\mathrm{C}: \mathrm{N}$ ratio required by the mushroom species. 
Significant variations in the amount of yield obtained among substrates clearly indicated the type and amount of nutritious components found in the growing substrates. This was lower than results obtained from [13] which was $29.07-77.38 \% \mathrm{BE}$ and [30] which was $68-$ $106 \%$ but most are comparable to $44-47.1 \%$ BE from [31] except pure sawdust and other sawdust containing substrates $\left(\mathrm{Cw}_{50}: \mathrm{Sd}_{50}\right.$, $\mathrm{Sd}_{50}: \mathrm{Sb}_{25}: \mathrm{Cw}_{25}$, and $\left.\mathrm{Sb}_{50}: \mathrm{Sd}_{50}\right), 43.3-62.7 \% \mathrm{BE}$ from Iqbal et al. [16], and $67.5 \%$ average BE reported by Chang [2]. The difference might be due to substrate type, amount and type of supplementary substrate, and quality of spawn beside the environmental factors. It was also generalized from the data that the first flush yield was highest in all treatments followed by the second and third flush [32].

Matured oyster mushrooms were harvested for three consecutive flushes commonly in all substrates, but some produce more than 3 times. Other scientists also recorded similar results Tesfaw [33] got 4 flushes cottonseed and waste paper, [24] 3 flushes, and Beje et al. [13] obtained 3-4 flushes from coffee waste, corncobs, and sawdust.

Regard to stipe length and pileus diameter of harvested matured oyster mushroom in each flush and treatment bags were measured and found insignificantly different among substrates. Mean pileus diameter of harvested mature mushrooms was ranged from $5.5 \pm 0.5$ to $8 \pm 1.43 \mathrm{~cm}$. However, variations of pileus diameter among substrates were not significant. Similarly, mean stipe length of mature mushrooms among different substrates was ranged from $4.89 \pm 1.8$ to $8.34 \pm 0.29 \mathrm{~cm}$ and variations were not significant. However, in the present study, it is observed that substrates with lower yield gave mature oyster mushrooms with relatively shorter mean stipe length, lower pileus diameter though the variation was not significant. The mean stipe length and pileus diameter of the present study is relatively higher than other studies such as [1] and [31] recorded $4.8 \mathrm{~cm}$ and $3.4 \mathrm{~cm}$ stipe length in sugarcane bagasse and sawdust, respectively. In this study, big mature mushrooms with wider pileus diameter and longer stipe length were observed from substrates, which contained fewer number fruit body accompanied bunches. This may be because of less localized nutrient and space competition that existed in fewer fruit body containing bunches.

\section{CONCLUSION}

The present study demonstrates that $P$. ostreatus (Jacq. ex Fr.) P. Kummer successfully grown and obtained yield in all substrates except pure C. africana sawdust and some combination substrates those contain sawdust.

With regard to the amount of yield obtained, $\mathrm{Cw}$, performed the best, followed by $\mathrm{Sb}$, and combination substrates such as $\mathrm{Cw}_{50}: \mathrm{Sb}_{50}$, $\mathrm{Cw}_{50}: \mathrm{Sb}_{25}: \mathrm{Sd}_{25}$, and $\mathrm{Sb}_{50}: \mathrm{Cw}_{25}: \mathrm{Sd}_{25}$ which can be used in the smallscale cultivation of $P$. ostreatus (Jacq. ex Fr.) P. Kummer.

The highest yield of $P$. ostreatus (Jacq. ex Fr.) P. Kummer was obtained from $\mathrm{Cw}$ where readily available substrates in the study area and a high biomass exist in the country. This indicates the possibility of managing coffee waste through the production of P. ostreatus (Jacq. ex Fr.) P. Kummer that compensate protein gap of the country besides keeping of the environmental clean.

In Ethiopia, there are large amounts of lignocellulosic wastes, generated through agro-industrial activities each year and disposed of into the environment without any treatment, which are leading to serious environmental pollution. However, it has the chance to convert into nutritious and medicinal mushroom, P. ostreatus, through cultivation of it.

\section{ACKNOWLEDGMENT}

First, we gratefully acknowledge Mizan-Tepi University for financial support for the completion of this work. Next to this our special recognition goes to Tepi National Spice Center, Pathology Laboratory, for allowing and provided us laboratory service. In addition, the generous support and contribution of all my friends and colleagues are deeply acknowledged.

\section{REFERENCES}

1. Zhang YH. Reviving the carbohydrate economy via multiproduct lignocellulose bioefineries. J Ind Microbiol Biotechnol 2008;35:367-75.

2. Chang ST. Mushroom cultivation using the "ZERI" principle: Potential for application in Brazil. Micol Appl Int 2007;19:33-4.

3. Dundar A, Acay H, YildizA. Effect of using different lignocellulosic wastes for cultivation of Pleurotus ostreatus (Jacq.) P. Kumm. On mushroomyield, chemical composition and nutritional value. Afr J Biotechnol 2009;18:662.

4. Imtiaj A, Rahman SA. Economic viability of mushroom cultivation to poverty reduction in Bangladidesh. Trop Subtrop Agroecosyst 2008;8:93-9.

5. Beteez A, Kustudia M. Mushroom Cultivation and Marketing Horticulture Production. Guide. Abstract: ATTRA Publication; 2004. p. 1-25.

6. Chiu SW, Moore D. Threats to biodiversity caused by the traditional mushroom cultivation in China. In: Moore D, Nauta M, Rotheroe M, editors. Fungal Conservation: The $21^{\text {st }}$ Century Issue. Cambridge, USA: Cambridge University Press; 2001.

7. Rai, RD, Ahlawat OP. Edible fungi: Biotechnological approaches. Appl Mycol Biotechnol 2002;2:87-111.

8. Stamets P. Growing Gourmet and Medicinal Mushrooms. Berkeley: Ten Speed Press; 2000.

9. Chang ST, Lau OW, Cho KY. The cultivation and nutritional value of Pleurotus sajor caju. Eur J Appl Microbiol 1981;12:58-62.

10. Atikpo M, Onokpise O, Abazinge M, Louime C, Dzomeku M, Boateng L, et al. Sustainable mushroom production in Africa: A case study in Ghana. Afr J Biotechnol 2008;7:249-53.

11. Dawit A. Mushroom Cultivation: A Practical Approach. Addis Ababa, Ethiopia: Berhanena Selam Printing Enterprise; 1998.

12. Ersado M. Inventory of Woody Species in Bonga Forest. Institute of Biodiversity Conservation and Research. Addis Ababa, Ethiopia: Technical Report No. 1; 2001.

13. Beje G, Diriba M, Dawit A. Evaluation of locally available substrates for cultivation of oyster mushroom (Pleurotus ostreatus) in Jimma, Ethiopia. Afr J Microbiol Res 2012;7:2228-37.

14. Oei P. Small-scale Mushroom Cultivation: Oyster, Shiitake and Wood Ear Mushrooms. Netherlands: Agromisa Foundation and CTA; 2005.

15. Kivaisi AK. Mushroom Cultivation in Tanzania. Dar es Salam: Amelia Kajumulo Kivaisi; 2007.

16. Iqbal SM, Rauf CA, Sheikh MI. Yield performance of oyster mushroom on different substrates. Int J Agric Biol 2005;7:900-3.

17. Peng JT, Lee CM, Tsai YF. Effect of rice Bran on the production of different king oyster mushroom strains during bottle cultivation. J Agric Res 2000;49:60-7.

18. Adebayo EA, Martinze-Carrara D. Oyster mushroom (Pleurotus) are useful for utilizing liginocellulosic biomass. Afr J Biotechnol 2014;14:53-67.

19. Howard RL, Abotsi E, Jasen V, Rensburg EL, Howard S. Lignocellulose biotechnology issues of bioconversion and enzyme production. Afr J Biotechnol 2003;2:602-19.

20. Cohen A, Dorffling K, Bettin D, Hahn H. Abscisic acid and cytokinins as possible root to shoot signals in xylem sap of rice plants in drying 
soil. Aust J Plant Physiol 2002;20:109-15.

21. Olumide OJ. Economic analysis of mushroom marketing as a copping strategy for poverty reduction in Ondo State, Nigeria. Afr Crop Sci Conf Proc 2007;8:1255-60.

22. Carrera MD. Simple techinology to cultivate Pleurotus on coffee pulp in the tropics. Mush Sci 1989;12:169-78.

23. Fekadu A. Cultivation of Oyster mushroom (Pleurotus ostreatus) in teff straw. Glob Adv Res J Med Med Sci 2014;3:205-15.

24. Girmay Z, Gorems W, Birhanu G, Zewdie S. Growth and yield performance of Pleurotus ostreatus (Jacq. Fr.) kumm (oyster mushroom) on different substrates. AMB Express 2016;6:87.

25. Chang ST, Miles PG Mushrooms: Cultivation, Nutritional Value, Medicinal Effect, and Environmental Impact. $2^{\text {nd }}$ ed. Boca Raton: CRC Press; 2004.

26. Ahmed S. Development of Mushroom Varieties Suitable for Rural Level in Bangladesh. Report Presented in BARC Annual Review Programme; 1998. p. 72-3.

27. Fan L, Pandey A, Mohan R, Soccol CR. Use of various coffee industry residues for the cultivation of Pleurotus ostreatus in solid state fermentation. Acta Biotechnol 2000;20:41-52.

28. Shah ZA, Ashraf M, Ishtiaq M. Comparative study on cultivation and yield performance of oyster mushroom (Pleurotus ostreatus) on different substrates (wheat straw, leaves, sawdust). Pak J Nutr 2004;3:158-60.

29. Daba AS, Kabeil SS, Botros WA, El-Saadani MA. Production of mushroom (Pleurotus ostreatus) in Egypt as a source of nutritional and medicinal food. World J Agric Sci 2008;4:630-4.

30. Salmones D, Mata G, Waliszewski KN. Comparative culturing of Pleurotus spp. on coffee pulp and wheat straw: Biomass production and substrate biodegradation. Bioresour Technol 2005;96:537-44.

31. Kimenju JW, Odero OM, Mutitu EW, Wachra PM, Narla RD, Muiru WM. Suitability of locally available substrates for oyster mushroom (Pleurotus ostreatus) cultivation in Kenya. Asian J Plant Sci 2009;8:510-4.

32. Shen Q, Royse DJ. Effects of nutrient supplements on biological efficiency, quality and crop cycle time of maitake (Grifolafrondosa). J Appl Microbiol Biotechnol 2001;57:74-8.

33. Tesfaw A, Abebe T, Gebre K. Optimization of oyster (Pleurotus ostreatus) mushroom cultivation using locally available substrates and materials in Debre Berhan, Ethiopia. J App Biol Biotech $2015 ; 3: 15-20$

\section{How to cite this article:}

Bitew TD, Mandefro SA. Substrate optimization for cultivation of

Pleurotus ostreatus on lignocellulosic wastes (coffee, sawdust, and

sugarcane bagasse) in Mizan-Tepi University, Tepi Campus, Tepi Town.

J App Biol Biotech. 2018;6(04):14-20. DOI: 10.7324/JABB.2018.60403 